\title{
Genetic Polymorphisms and Cerebral Palsy in Very Preterm Infants
}

\author{
KARIN B. NELSON, JAMES M. DAMBROSIA, DAVID M. IOVANNISCI, SUZANNE CHENG, \\ JUDITH K. GRETHER, AND EDWARD LAMMER
}

National Institute of Neurological Disorders and Stroke, Bethesda, MD 20892-1447 (KBN, JMD); Children's Hospital and Research Center at Oakland, CA 94609-1673 (DMI, EL); Department of Human Genetics, Roche Molecular Systems, Inc. Alameda, CA 94501-1145 (SC); and the California Department of Health Services, CA 94612 (JKG)

\begin{abstract}
In the present study, we examine whether selected genetic polymorphisms contribute to the development of cerebral palsy (CP) in very preterm infants. Subjects were 96 singleton infants with later-diagnosed $\mathrm{CP}$ and 119 control children, white nonHispanic ( $\mathrm{n}$ for $\mathrm{CP}=74$, controls $=88$ ) or white Hispanic $(\mathrm{CP}$ $=22$, controls $=31)$, born $<32$ wk gestation. Presence of $\mathrm{CP}$ was identified through state service agencies, with review of medical records. DNA extracted from archived neonatal blood was genotyped using multi-locus polymerase chain reaction amplification and immobilized sequence-specific oligonucleotide probes. Single nucleotide polymorphisms (SNPs) showing evidence of association with development of $\mathrm{CP}$ were endothelial nitric oxide synthase (eNOS) A(-922)G, factor 7 (F7) arg353gln and del(-323)10bp-ins, and lymphotoxin A (LTA) thr26asn. In white non-Hispanic children, beta-2 adrenergic receptor gln $27 \mathrm{glu}$ was associated with CP risk; in Hispanic children, plasminogen activator inhibitor-1 (PAI-1) 4G(-675)5G and G11053T were associated with risk of $\mathrm{CP}$. In a logistic regression considering these SNPs simultaneously in non-Hispanics, an association with CP was observed for heterozygotes of eNOS -922 (OR 3.0, CI
\end{abstract}

\section{ABSTRACT}

1.4-6.4), F7 (OR 2.7, CI 1.1-6.5), LTA (OR 2.1, CI 1.0-4.6), and PAI-1 (OR 3.2, CI 1.2-8.7). Factor 5, Factor 2, methylene tetrahydrofolate reductase, tumor necrosis factor-alpha, and other SNPs tested were not significantly associated with CP risk. We conclude that further study of genetic factors that may influence susceptibility to $\mathrm{CP}$ in very preterm infants is warranted. (Pediatr Res 57: 494-499, 2005)

$\quad$ Abbreviations
ADRB-2, adrenergic receptor beta-2
CI, confidence interval
CP, cerebral palsy
eNOS, endothelial nitric oxide synthase (NOS3)
F2, coagulation factor 2, prothrombin
F7, coagulation factor 7
LTA, lymphotoxin
OR, odds ratio
PAI-1, plasminogen activator inhibitor 1
SNP, single nucleotide polymorphism
TNF, tumor necrosis factor

Genomic analysis has been applied to a wide range of complex disorders, including asthma, cystic fibrosis, cancer, arthritis, and also schizophrenia and autism. We could identify no study that has taken cerebral palsy (CP) as a phenotype for genomic investigation. Given the paucity of known prenatal predictors of $\mathrm{CP}$ in very preterm infants, the apparent differences in vulnerability of different infants, and the possibility of racial/ethnic differences in susceptibility to $\mathrm{CP}$ and to chronic lung disease, we considered the possibility that genetic factors might play a role in $\mathrm{CP}$ occurring

Received November 8, 2004; accepted January 4, 2005

Correspondence: Karin B. Nelson, M.D., National Institutes of Health Building 10, Room 5S220, Bethesda, MD 20892-1447; e-mail: knelson@helix.nih.gov

Role of funding sources: Dr. Cheng is an employee of Roche Molecular Systems, Inc., which supplied the research reagents used for genotyping. This research was supported in part by a grant (NS35573-01) from the National Institute of Neurological Disorders and Stroke, and intramural NINDS funds supported the laboratory work.

DOI: 10.1203/01.PDR.0000156477.00386.E7 in children born very preterm. We report a pilot study using a candidate single nucleotide polymorphism (SNP) approach in children born before 32 wk gestation.

Infants born very prematurely are at relatively high risk for CP. To explore the possibility that genetic factors contribute to $\mathrm{CP}$ in these very preterm infants, we undertook a study of SNPs in neonatal blood, using a research panel of candidate SNPs developed for the investigation of cardiovascular disease. Many of the SNPs included are potentially relevant to pediatric stroke (1), and to coagulation and inflammatory responses that may play a role in $\mathrm{CP}$ in preterm infants. We examined whether these SNPs were present more often in neonatal blood of infants with later-diagnosed CP born before 32 wk gestation, as compared with control infants of similar gestational age distributions and racial group.

Despite limited sample size, this exploratory study suggests that further investigation of genetic polymorphisms as contrib- 
utors to susceptibility to $\mathrm{CP}$ in very preterm infants is warranted.

\section{METHODS}

Case and control subjects whose mothers were white non-Hispanic or white Hispanic were drawn from a larger study population of singleton infants born at less than $32 \mathrm{wk}$ gestation with birth weights less than $2000 \mathrm{~g}$, born between 1988 and 1994 in hospitals offering level 2 or 3 neonatal care in northern California, and who survived at least to age 2 y (2). Maternal race was determined by self-identification from the California birth certificate. The presence of $\mathrm{CP}$ was identified through review of medical records of children enrolled in two California state service agencies mandated to provide services to children with disabling $\mathrm{CP}$ without regard to citizenship or financial status. Final diagnosis of $\mathrm{CP}$ and determination of case or control status was at age $4 \mathrm{y}$ or at the time of death for children who died between 2 and $4 \mathrm{y}$ of age. Children born to women with preeclampsia or severe systemic disease, or born within $3 \mathrm{~h}$ of admission for delivery, were excluded unless there were indicators of chorioamnionitis. A total of 232 control children and 99 with cerebral palsy were excluded from the potential study population of 7978 children on the basis of these criteria.

$\mathrm{CP}$ was defined as a chronic disability of brain origin, characterized by aberrant control of movement or posture, appearing early in life, and not the result of progressive disease. Children whose $\mathrm{CP}$ was acquired through postnatal infection or injury were excluded. Controls were children not receiving state-supported services for $\mathrm{CP}$ who met the same birth weight and gestational age criteria as cases. The pool of potential controls was divided into $250 \mathrm{~g}$ birth weight strata by birth year, and two controls per case were randomly selected from within each birth weight-birth year stratum. Details of case and control selection are available elsewhere (2). The study was approved by the California Committee for the Protection of Human Subjects, with a waiver of informed consent because of early anonymization and the unlikeliness of a result with immediate clinical implications.

Genotyping was performed using a multi-locus polymerase chain reaction (PCR) and probe-based hybridization research assay developed for research use by Roche Molecular Systems, essentially as previously described (3). Briefly, each sample was amplified using a pool of biotinylated primer pairs targeting 31 genomic fragments. Amplified fragments were then hybridized to sequence-specific oligonucleotide probes immobilized in a linear array on nylon membranes and detected colorimetrically. Interpretation of the probe signals was performed independently by two investigators blinded to casecontrol status and other clinical and demographic characteristics. Probe specificities were previously confirmed by sequencing or use of DNAs genotyped independently by other methods such as restriction fragment length polymorphism analysis.

The SNPs included in the Roche Molecular Systems cardiovascular panel evaluated in this study are shown in Table 1. For two children, two specimens of blood drawn on separate days were submitted under different code numbers; results were identical in both measurements (only one sample from each child was included in these results.)

Because this was an exploratory study, no correction was made for multiple comparisons and all comparisons are reported. Consistency with HardyWeinberg equilibrium was tested for cases and controls. Comparisons of genotypic distributions were conducted separately in the total study sample and in white non-Hispanic and white Hispanic children, using the Fisher-FreemanHalton exact $\chi^{2}$ test (4). Logistic regression models were constructed to describe the joint effect of discriminating individual SNPs on CP; sample size and the rarity of some genotypes limited further modeling of interactions. Recursive partitioning was used to explore the ability of the measured SNPs to discriminate between cases and controls and their relationship to one another. The individual SNPs whose genotypes most clearly discriminated cases from controls were entered into CART (5). The analysis identified the hierarchy of

Table 1. Single nucleotide polymorphisms studied in very preterm infants

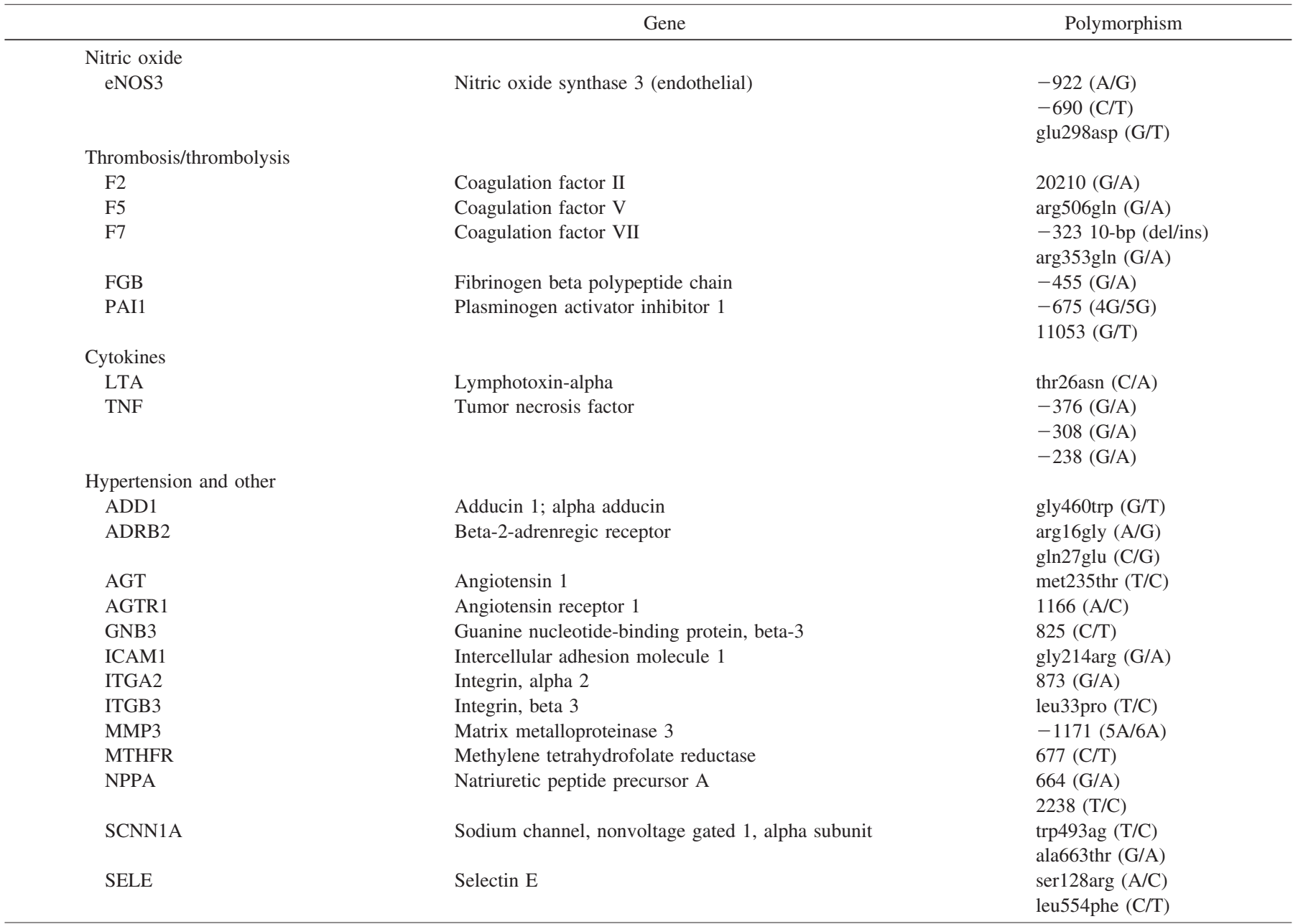


SNP genotype combinations that provided the best classification of cases and controls.

\section{RESULTS}

Means and distributions of birth weight, gestational age, and proportion male were similar in the 96 children with $\mathrm{CP}$ and 119 control children (Table 2). Spastic diplegia was the most frequent $\mathrm{CP}$ subtype in this as in other studies of very preterm infants. In the children evaluated in this study, hemiplegia was the CP subtype observed in $24 \%$ of white non-Hispanic children and in $4.5 \%$ of white Hispanic children, compared with $10 \%$ and $3 \%$, respectively, in the larger study population.

Of the 31 SNPs examined, only one - eNOS (-922) deviated from Hardy-Weinberg equilibrium among the 119 controls.

Children with CP differed from control children with respect to four SNPs: eNOS A(-922)G, F7 del(-323)10bp-ins and $\arg 353 \mathrm{gln}$, and LTA thr26asn. In white non-Hispanic children, cases differed from controls with regard to genotypic frequencies of ADRB-2 gln27glu. Among white Hispanic children, two PAI-1 SNPs, -675 (G5/G4) and 11053 (G/T), were different in frequency in children with CP compared with control children. For all these variants, gestational age and birthweight were closely similar in each haplotype group.

SNPs related to nitric oxide. More children with $\mathrm{CP}$ than control children were heterozygotes for eNOS A(-922)G, and fewer were homozygous for the $G$ allele (Table 3). Heterozygotes were comparable in birth weight and gestational age with children of both homozygous genotypes. For another eNOS SNP, glu298asp, trends paralleled observations for eNOS (-922). Most children who were heterozygous for one of these eNOS SNPS were also heterozygous for the other. Both (-922) and 298 heterozygous genotypes were present in $33.3 \%$ of children with CP, $14.3 \%$ of controls. For a third and less frequent eNOS variant, C(-690)T, no difference in genotypic frequencies was observed between children with $\mathrm{CP}$ and controls. The eNOS variants were not related to $\mathrm{CP}$ subtype.

SNPs related to thrombosis or thrombolysis. More children with CP than control children were heterozygous or homozygous for the minor alleles of the two F7 mutations examined, F7 arg353gln and del(-323)10bp-ins. In non-Hispanic children, $21.9 \%$ of children with CP and $10.9 \%$ of controls were het-

Table 2. Demographic characteristics of control children and children with cerebral palsy

\begin{tabular}{|c|c|c|}
\hline & $\begin{array}{c}\text { Control children } \\
n=119\end{array}$ & $\begin{array}{l}\text { Children with } \\
\text { cerebral palsy } \\
\quad n=96\end{array}$ \\
\hline Birth weight & 1141.7 (336.7) & $1142.8(358.0)$ \\
\hline Gestational age & $28.0(2.8)$ & $27.9(2.7)$ \\
\hline Male & $68 \quad(57.1)$ & $62 \quad(64.6)$ \\
\hline \multicolumn{3}{|l|}{ Race } \\
\hline White-Hispanic & $31 \quad(26.1)$ & $22 \quad(22.9)$ \\
\hline White non-Hispanic & $88 \quad(73.9)$ & $74 \quad(77.1)$ \\
\hline \multicolumn{3}{|l|}{ CP Subtype } \\
\hline Spastic diplegia & & $45 \quad(46.9)$ \\
\hline Spastic quadriplegia & & $30 \quad(31.2)$ \\
\hline Hemiparesis & & $18 \quad(18.8)$ \\
\hline Type unknown & & $3 \quad(3.1)$ \\
\hline
\end{tabular}

erozygous for both $\mathrm{F} 7$ variants, while 5.2 and $0.8 \%$, respectively, were homozygous. No association of F7 to CP subtype was observed.

For plasminogen activator inhibitor 1 (PAI-1), genotypic frequencies differed in the two racial/ethnic groups examined: among white non Hispanics, more than $80 \%$ of control children carried the $4 \mathrm{G}$ variation in either heterozygous or homozygous form, while the $5 \mathrm{G} / 5 \mathrm{G}$ genotype was more prevalent among white Hispanic control children. Among non-Hispanics, there was little difference with respect to the (-675) 5G/4G genotype in cases as compared with control children. In contrast, among white Hispanic children, the relatively uncommon $4 \mathrm{G}$ allele was observed more frequently in children with CP (Table 3.)

Among non-Hispanic children, the homozygous TT genotype for $11053 \mathrm{G} / \mathrm{T}$ was observed more frequently in children with $\mathrm{CP}$ than in controls, while among Hispanics the T allele was apparently protective: six of the seven Hispanic children lacking the T allele for PAI-1 11053 had CP, while more children with the $\mathrm{T}$ allele were controls. Thus in univariate analysis, the PAI-1 (-675) 4G allele was associated with risk of $\mathrm{CP}$ in Hispanic but not in non-Hispanic children. The $11053 \mathrm{~T}$ allele was associated with decreased $\mathrm{CP}$ risk in Hispanic children and with a trend toward increased risk in nonHispanics. The proportion of Hispanic children who were heterozygous for both tested PAI-1 SNPS was similar in cases and controls.

No significant association with $\mathrm{CP}$ was observed for Factor II (prothrombin, F2) G20210A or Factor V Leiden arg506glu (Table 3). The frequency of heterozygous genotypes for these genes in white non-Hispanic controls was $1.1 \%$ for Factor II and $5.7 \%$ for Factor V, comparable with reports in other Caucasian pediatric and adult populations (6). No child in this study, case or control, was F2 20210AA. Of the five heterozygotes for the F2 G20210A mutation, four were children with $\mathrm{CP}$. The F5 and methylene tetrahydrofolate reductase (MTHFR) SNPs tested were not associated with CP risk in either racial subgroup.

SNPs related to cytokine function. More children with CP than control children were heterozygotes for LTA thr26asn. Three TNF-alpha variants were not associated with differential $\mathrm{CP}$ risk. There was no relation of LTA genotype with CP subtype.

SNPs related to hypertension and other. In non-Hispanic children, the beta- 2 adrenergic receptor gln 27 glu glu/glu genotype was more frequent among children with $\mathrm{CP}$, while the $\mathrm{gln} / \mathrm{glu}$ heterozygote was more frequently in controls. In both racial groups but more markedly among Hispanics, homozygosity for Arg16 was associated with gestational age 2 weeks lower than observed in homozygotes for Gly16. No differences in genotypic frequencies were observed in SNPs for angiotensin or its receptor, intercellular adhesion molecule $1, \mathrm{G}$ protein beta3, integrin, alpha 2 or beta3 subunits, matrix metalloproteinase 3, natriuretic peptide precursor A, non voltage-gated sodium channel, alpha subunit, or for selectins or integrins.

Possible gene-gene relationships. For several genes, two SNPs were examined in this study and at least one of these was associated with CP (eNOS, F7, PAI-1, ADRB-2). As indicated, most children who were heterozygous for one of the pair were 
Table 3. Genotypic distributions in very premature control children and children with cerebral palsy

\begin{tabular}{|c|c|c|c|c|c|c|c|c|}
\hline \multirow[b]{2}{*}{ Gene symbol } & & \multirow[b]{2}{*}{ Genotype } & \multicolumn{2}{|c|}{ ALL CHILDREN } & \multicolumn{2}{|c|}{ NON-HISPANIC } & \multicolumn{2}{|c|}{ HISPANIC } \\
\hline & & & $\begin{array}{c}\text { Control children } \\
n=119\end{array}$ & $\begin{array}{c}\text { Children with CP } \\
n=96\end{array}$ & $\begin{array}{c}\text { Control children } \\
n=88\end{array}$ & $\begin{array}{c}\text { Children with } \mathrm{CP} \\
n=74\end{array}$ & $\begin{array}{c}\text { Control children } \\
n=31\end{array}$ & $\begin{array}{c}\text { Children with CP } \\
n=22\end{array}$ \\
\hline & \multirow{2}{*}{$\frac{\text { Polymorphism }}{-922(\mathrm{~A} / \mathrm{G})^{*}, \dagger}$} & AG & 38 (31.9) & $51(51.1)$ & $31(35.2)$ & $43(58.1)$ & $7(22.6)$ & $8(36.4)$ \\
\hline & & GG & $16(13.5)$ & $5(5.2)$ & $13(14.8)$ & $4(5.4)$ & $3(9.7)$ & $1(4.5)$ \\
\hline & \multirow[t]{2}{*}{$-690(\mathrm{C} / \mathrm{T})$} & $\mathrm{CC}$ & $102(85.7)$ & $81(84.4)$ & $75(85.2)$ & $60(81.1)$ & $27(87.1)$ & $21(95.5)$ \\
\hline & & $\mathrm{CT}$ & $16(13.4)$ & $15(15.6)$ & $13(14.8)$ & $14(18.9)$ & $3(9.7)$ & $1(4.5)$ \\
\hline & \multirow[t]{3}{*}{ glu298asp (G/T) } & GG & $69(58.0)$ & $45(46.9)$ & $47(53.4)$ & $31(41.9)$ & $22(71.0)$ & 14 (63.6) \\
\hline & & GT & $38(31.9)$ & $45(46.9)$ & $30(34.1)$ & $37(50.0)$ & $8(25.8)$ & $8(36.4)$ \\
\hline & & TT & $12(10.1)$ & $6(6.2)$ & $11(12.5)$ & $6(8.1)$ & $1(3.2)$ & $0(0.0)$ \\
\hline \multirow{3}{*}{$\mathrm{F} 2$} & \multirow{3}{*}{$20210(\mathrm{G} / \mathrm{A})$} & GG & $115(99.1)$ & $91(95.8)$ & $86(98.9)$ & $69(94.5)$ & $29(100.0)$ & $22(100.0)$ \\
\hline & & GA & $1(0.9)$ & $4(4.2)$ & $1(1.1)$ & $4(5.5)$ & - & - \\
\hline & & AA & - & - & - & - & - & - \\
\hline & & ins ins & $3(2.5)$ & $6(6.3)$ & $2(2.3)$ & $6(8.1)$ & $1(3.2)$ & $0(0.0)$ \\
\hline & $\arg 353 \operatorname{gln}(\mathrm{G} / \mathrm{A})^{*}, \dagger$ & GG & $100(84.0)$ & $69(71.9)$ & $75(85.2)$ & $49(66.2)$ & $25(80.6)$ & $20(90.9)$ \\
\hline & & GA & $18(15.1)$ & $22(22.9)$ & $13(14.8)$ & $50(27.0)$ & $5(16.1)$ & $2(9.1)$ \\
\hline & & AA & $1(0.9)$ & $5(5.2)$ & $0(0.0)$ & $5(6.8)$ & $1(3.2)$ & $0(0.0)$ \\
\hline FGB & $-455(\mathrm{G} / \mathrm{A})$ & GG & $75(63.6)$ & $68(70.8)$ & $55(63.2)$ & $54(73.0)$ & $20(64.5)$ & $14(63.6)$ \\
\hline & & GA & $37(31.3)$ & $26(27.1)$ & $29(33.3)$ & $19(25.7)$ & $8(25.8)$ & $7(31.8)$ \\
\hline & & AA & $6(5.1)$ & $2(2.1)$ & $3(3.4)$ & $1(1.3)$ & $3(9.7)$ & $1(4.5)$ \\
\hline PAI1 & $-675(\mathrm{G} 5 / \mathrm{G} 4) \ddagger$ & G5 G5 & $34(28.6)$ & $24(25.0)$ & $16(18.2)$ & $18(24.3)$ & $18(58.1)$ & $6(27.3)$ \\
\hline & & G5 G4 & $51(42.8)$ & $45(46.9)$ & $39(44.3)$ & 33 (44.6) & $12(38.7)$ & $12(54.5)$ \\
\hline & & G4 G4 & 34 (28.6) & $27(28.1)$ & $33(37.5)$ & $23(31.1)$ & $1(3.2)$ & $4(18.2)$ \\
\hline & $11053(\mathrm{G} / \mathrm{T}) \ddagger$ & GG & $26(21.8)$ & $17(17.7)$ & $25(28.4)$ & $11(14.9)$ & $1(3.2)$ & $6(27.3)$ \\
\hline & & GT & $59(49.6)$ & $46(47.9)$ & $46(52.3)$ & $40(54.1)$ & $13(41.9)$ & $6(27.3)$ \\
\hline & & AG & $26(21.8)$ & $24(25.0)$ & $23(26.1)$ & $21(28.4)$ & $3(9.7)$ & $3(13.6)$ \\
\hline & & AA & $1(0.8)$ & $0(0.0)$ & $1(1.1)$ & $0(0.0)$ & - & - \\
\hline & $-238(\mathrm{G} / \mathrm{A})$ & GG & $107(89.9)$ & $88(91.7)$ & $80(90.9)$ & $69(93.2)$ & $27(87.1)$ & $19(86.4)$ \\
\hline & & GA & $12(10.1)$ & $8(8.3)$ & $8(9.1)$ & $5(6.8)$ & $4(12.9)$ & $3(13.6)$ \\
\hline & & AA & - & - & - & & - & - \\
\hline ADD1 & gly460trp (G/T) & GG & $72(61.0)$ & $67(69.8)$ & $53(60.9)$ & $52(70.3)$ & $19(61.3)$ & $15(68.2)$ \\
\hline & & GT & $36(30.5)$ & $27(28.1)$ & $26(29.9)$ & $20(27.0)$ & $10(32.3)$ & $7(31.8)$ \\
\hline & & TT & $10(8.5)$ & $2(2.1)$ & $8(9.2)$ & $2(2.7)$ & $2(6.4)$ & $0(0.0)$ \\
\hline ADRB2 & $\arg 16$ gly $(\mathrm{A} / \mathrm{G})$ & $\mathrm{AA}$ & $16(13.4)$ & $13(13.5)$ & $12(13.7)$ & $10(13.5)$ & $4(12.9)$ & $3(13.6)$ \\
\hline & & $\mathrm{AG}$ & $61(51.3)$ & $43(44.8)$ & $45(51.1)$ & $32(43.2)$ & $16(51.6)$ & $11(50.0)$ \\
\hline & & GG & $42(35.3)$ & $40(41.7)$ & $31(35.2)$ & $32(43.2)$ & $11(35.5)$ & $8(36.4)$ \\
\hline & gln 27 glu $(\mathrm{C} / \mathrm{G}) \dagger$ & $\mathrm{CC}$ & $50(42.0)$ & $40(41.7)$ & $33(37.5)$ & $28(37.8)$ & $17(54.8)$ & $12(54.6)$ \\
\hline & & CG & $56(47.1)$ & $37(38.5)$ & $46(52.3)$ & $28(37.8)$ & $10(32.3)$ & $9(40.9)$ \\
\hline & & GG & $13(10.9)$ & $19(19.8)$ & $9(10.2)$ & $18(24.3)$ & $4(12.9)$ & $1(4.5)$ \\
\hline AGT & met235thr (T/C) & TT & $31(26.1)$ & $29(30.2)$ & $26(29.6)$ & $27(36.5)$ & $5(16.1)$ & $2(9.1)$ \\
\hline & & $\mathrm{TC}$ & 57 (47.9) & $43(44.8)$ & $45(51.1)$ & $34(45.9)$ & $12(38.7)$ & $9(40.9)$ \\
\hline & & $\mathrm{CC}$ & $31(26.0)$ & $24(25.0)$ & $17(19.3)$ & 13 (17.6) & $14(45.2)$ & $11(50.0)$ \\
\hline AGTR1 & $1166(\mathrm{~A} / \mathrm{C})$ & AA & $58(48.7)$ & $43(44.8)$ & $44(50.0)$ & 34 (45.9) & $14(45.2)$ & $9(40.9)$ \\
\hline & & $\mathrm{AC}$ & $51(42.9)$ & 45 (46.9) & $38(43.2)$ & $33(44.6)$ & 13 (41.9) & $12(54.5)$ \\
\hline & & $\mathrm{CC}$ & $10(8.4)$ & $8(8.3)$ & $6(6.8)$ & $7(9.5)$ & $4(12.9)$ & $1(4.5)$ \\
\hline GNB3 & $825(\mathrm{C} / \mathrm{T})$ & $\mathrm{CC}$ & $47(39.5)$ & $40(41.7)$ & $40(45.5)$ & $32(43.2)$ & $7(22.6)$ & $8(36.3)$ \\
\hline & & $\mathrm{CT}$ & $52(43.7)$ & $42(43.7)$ & $33(37.5)$ & $32(43.2)$ & $19(61.3)$ & $10(45.5)$ \\
\hline & & $\mathrm{TT}$ & $20(16.9)$ & 14 (14.6) & $15(17.0)$ & $10(13.5)$ & $5(16.1)$ & $4(18.2)$ \\
\hline ICAM1 & gly214arg (G/A) & GG & $87(73.1)$ & $77(80.2)$ & $67(76.1)$ & $63(85.1)$ & $20(64.5)$ & $14(63.6)$ \\
\hline & & GA & $29(24.5)$ & $18(18.8)$ & $18(20.5)$ & $11(14.9)$ & $11(35.5)$ & $7(31.8)$ \\
\hline
\end{tabular}


Table 3. Continued.

\begin{tabular}{|c|c|c|c|c|c|c|c|c|}
\hline \multirow[b]{2}{*}{ Gene symbol } & \multirow[b]{2}{*}{ Polymorphism } & \multirow[b]{2}{*}{ Genotype } & \multicolumn{2}{|c|}{ ALL CHILDREN } & \multicolumn{2}{|c|}{ NON-HISPANIC } & \multicolumn{2}{|c|}{ HISPANIC } \\
\hline & & & $\begin{array}{c}\text { Control children } \\
n=119\end{array}$ & $\begin{array}{c}\text { Children with CP } \\
n=96\end{array}$ & $\begin{array}{c}\text { Control children } \\
n=88\end{array}$ & $\begin{array}{c}\text { Children with CP } \\
n=74\end{array}$ & $\begin{array}{c}\text { Control children } \\
\quad n=31\end{array}$ & $\begin{array}{c}\text { Children with CP } \\
n=22\end{array}$ \\
\hline & & GA & $53(44.9)$ & $46(47.9)$ & $41(47.1)$ & $34(45.9)$ & $12(38.7)$ & $12(54.5)$ \\
\hline & & AA & $18(15.3)$ & $15(15.6)$ & $11(12.6)$ & $12(16.2)$ & 7 (22.6) & $3(13.7)$ \\
\hline \multirow{3}{*}{ ITGB3 } & leu33pro (T/C) & TT & $92(77.3)$ & $69(72.6)$ & $68(77.3)$ & $51(68.9)$ & $24(77.4)$ & $18(85.7)$ \\
\hline & & $\mathrm{TC}$ & $24(20.2)$ & $25(26.3)$ & $19(21.6)$ & $22(29.7)$ & $5(16.1)$ & $3(14.3)$ \\
\hline & & $\mathrm{CC}$ & $3(2.5)$ & $1(1.1)$ & $1(1.1)$ & $1(1.4)$ & $2(6.5)$ & $0(0.0)$ \\
\hline \multirow[t]{3}{*}{ MMP3 } & $-1171(\mathrm{~A} 5 / \mathrm{A} 6)$ & A5A5 & $20(16.9)$ & $16(16.7)$ & $15(17.2)$ & $15(20.3)$ & $5(16.1)$ & $1(4.5)$ \\
\hline & & A5A6 & $54(45.8)$ & $45(46.9)$ & $44(50.6)$ & $40(54.1)$ & $10(32.3)$ & $5(22.7)$ \\
\hline & & A6A6 & $44(37.2)$ & $35(36.4)$ & $28(32.2)$ & $19(25.6)$ & $16(51.6)$ & $16(72.7)$ \\
\hline \multirow[t]{3}{*}{ MTHFR } & $677(\mathrm{C} / \mathrm{T})$ & $\mathrm{CC}$ & $49(41.2)$ & $45(46.9)$ & $40(45.5)$ & $36(48.6)$ & $9(29.0)$ & $4(18.2)$ \\
\hline & & $\mathrm{CT}$ & $54(45.4)$ & 40 (41.7) & $39(44.3)$ & $32(43.2)$ & $15(48.4)$ & $13(59.1)$ \\
\hline & & TT & $16(13.4)$ & $11(11.4)$ & $9(10.2)$ & $6(8.1)$ & 7 (22.6) & $5(22.7)$ \\
\hline \multirow[t]{6}{*}{ NPPA } & 664 (G/A) & GG & $110(92.4)$ & $87(90.6)$ & $81(92.0)$ & $65(87.8)$ & $29(93.5)$ & $22(100.0)$ \\
\hline & & GA & $9(7.6)$ & $9(9.4)$ & $7(8.0)$ & $9(12.2)$ & $2(6.5)$ & $0(0.0)$ \\
\hline & & AA & - & - & - & - & - & - \\
\hline & 2238 (T/C) & $\mathrm{TT}$ & $86(72.3)$ & $73(76.0)$ & $61(69.3)$ & $57(77.0)$ & $25(80.6)$ & $16(72.7)$ \\
\hline & & $\mathrm{TC}$ & $31(26.1)$ & $20(20.8)$ & $25(28.4)$ & 14 (18.9) & $6(19.4)$ & $6(27.3)$ \\
\hline & & $\mathrm{CC}$ & $2(1.6)$ & $3(3.1)$ & $2(2.3)$ & $3(4.1)$ & - & - \\
\hline \multirow[t]{6}{*}{ SCNN1A } & $\operatorname{trp493ag}(\mathrm{T} / \mathrm{C})$ & TT & $118(99.2)$ & $92(95.8)$ & 87 (98.9) & $71(95.9)$ & $31(100.0)$ & $21(95.5)$ \\
\hline & & $\mathrm{TC}$ & $1(0.8)$ & $4(4.2)$ & $1(1.1)$ & $3(4.1)$ & $0(0.0)$ & $1(4.5)$ \\
\hline & & $\mathrm{CC}$ & - & - & - & - & - & - \\
\hline & ala663thr (G/A) & GG & $60(50.8)$ & $43(44.8)$ & $42(48.3)$ & $32(43.2)$ & $18(58.1)$ & $11(50.0)$ \\
\hline & & GA & $52(44.1)$ & $44(45.8)$ & $40(46.0)$ & 34 (45.9) & $12(38.7)$ & $10(45.5)$ \\
\hline & & AA & $6(5.1)$ & $9(9.4)$ & $5(5.7)$ & $8(10.8)$ & $1(3.2)$ & $1(4.5)$ \\
\hline \multirow[t]{6}{*}{ SELE } & ser128arg $(\mathrm{A} / \mathrm{C})$ & $\mathrm{AA}$ & $95(80.5)$ & $83(86.5)$ & $70(80.5)$ & $65(87.8)$ & $25(80.6)$ & $18(81.8)$ \\
\hline & & $\mathrm{AC}$ & $21(17.8)$ & $13(13.5)$ & $15(17.2)$ & $9(12.2)$ & $6(19.4)$ & $4(18.2)$ \\
\hline & & $\mathrm{CC}$ & $2(1.7)$ & $0(0.0)$ & $2(2.3)$ & $0(0.0)$ & - & - \\
\hline & leu554phe $(\mathrm{C} / \mathrm{T})$ & $\mathrm{CC}$ & $111(93.3)$ & $84(87.5)$ & $83(94.3)$ & $65(86.5)$ & $28(90.3)$ & $20(90.9)$ \\
\hline & & $\mathrm{CT}$ & $7(5.9)$ & $12(12.5)$ & $4(4.5)$ & $9(13.5)$ & $3(9.7)$ & $2(9.1)$ \\
\hline & & TT & $1(0.8)$ & $0(0.0)$ & $1(1.1)$ & $0(0.0)$ & - & - \\
\hline
\end{tabular}

$* p$-value $<0.05$ for distribution difference between all control children and all children with cerebral palsy.

$\dagger p$-value $<0.05$ for distribution difference between non-Hispanic control children and children with cerebral palsy.

$\ddagger p$-value $<0.05$ for distribution difference between Hispanic control children and children with cerebral palsy.

also heterozygous for the other, suggesting that these were in strong linkage disequilibrium. For eNOS, F7, and ADRB-2, children with $\mathrm{CP}$ were more often heterozygous for both SNPs than were control children.

We used recursive partitioning (see Methods) to explore possible gene-gene association with risk. Heterozygosity for both NOS -922 and F7 353 was associated with especially high risk; this combination was noted in $16.7 \%$ of non-Hispanic children with $\mathrm{CP}$, compared with $2.5 \%$ of non-Hispanic control children. Fifteen of the 17 (88\%) of subjects with this combination of heterozygous states were children with $\mathrm{CP}$.

We applied a logistic regression to the white non-Hispanic subgroup, including the heterozygous genotypes for four SNPs associated with CP risk in this study, as reported above, plus PAI-1 11053, to assess their joint effects. With this model, we obtained the following odds ratios and $95 \%$ confidence intervals (CI): eNOS OR 3.0 (CI 1.4-6.4), F7 OR 2.7 (1.1-6.5), LTA OR 2.1 (1.0-4.6) and PAI-1 OR 3.2 (1.2-8.7) (Table 4). ADRB-2 did not have significant effect in this model.

\section{DISCUSSION}

In this exploratory study, genotypic frequencies for variants in the eNOS, F7, LTA, PAI-1 and ADRB-2 genes were differentially distributed in children with $\mathrm{CP}$ as compared with control children. These factors may be indicators of risk for development of $\mathrm{CP}$ in very preterm infants.

The SNPs associated with risk of $\mathrm{CP}$ were not related to hemiplegic $\mathrm{CP}$ more than to other $\mathrm{CP}$ subtypes, so the $\mathrm{CP}$ related to these SNPs was probably not the result of single major-vessel strokes. The identified SNPs were not in genes such as those for factor $\mathrm{V}$ Leiden or prothrombin, under suspicion for their relationship with pediatric stroke; however, sample size did not permit evaluation of homozygosity for uncommon variants.

Birth weight and gestational age are important risk factors for $\mathrm{CP}$, so these factors were tightly controlled, and the distributions of these characteristics were similar in children with $\mathrm{CP}$ and controls in this study. For ADRB-2, homozygotes for $\arg 16$ were slightly younger at birth than were infants with the gly16 allele, as previously reported (7), but this SNP was not related to $\mathrm{CP}$ risk. For other studied genes whose genotype frequencies are known for other samples of Caucasian children or adults, the rates in our controls were comparable, suggesting that these factors are not importantly related to risk of premature birth.

This study was limited to infants whose mothers described themselves as white non-Hispanic or white Hispanic, the two white groups who constitute the majority of the population of 
Table 4. Heterozygosity for SNPs associated with cerebral palsy in very preterm infants, logistic regression, white non-Hispanic subjects

\begin{tabular}{lcc}
\hline & Odds ratio & (Confidence intervals) \\
\hline eNOS (-922) & 3.0 & $(1.4-6.4)$ \\
Factor 7 & 2.7 & $(1.1-6.5)$ \\
Lymphotoxin A & 2.1 & $(1.0-4.6)$ \\
PAI-1 11053 & 3.2 & $(1.2-8.7)$ \\
\hline
\end{tabular}

the geographic area studied. The Hispanic group was relatively small and contained few children with hemiplegic $\mathrm{CP}$; in the larger study from which this study group came there was also a lower proportion of hemiplegic $\mathrm{CP}$ in Hispanic than in non-Hispanic children. African-American or Asian-American children, each a minority in this birth cohort (AfricanAmerican 32.6\%, Asian-American 4.1\%) (2), were not included in this preliminary study. Other studies have found racial differences in the association of intrauterine exposure to infection with $\mathrm{CP}(2,9)$, and with respiratory disease $(10,11)$, associated with $\mathrm{CP}$ in very preterm infants. Differing genotypic frequencies in different racial/ethnic groups may be part of the explanation for these disparities.

CP was well ascertained in this study but we did not have systematic information on results of neuroimaging, and so do not know which infants with $\mathrm{CP}$ had strokes or other specific patterns of brain pathology. Infants of preeclamptic mothers and of women who delivered rapidly after admission are under-represented, as dictated by the original purpose for which the study group was assembled (12). Some coagulation disorders predispose to preeclampsia and to placental conditions such as abruption that might lead to maternal hemorrhage and therefore to precipitate delivery, so under-representation may have led to under-estimation of the association of tested polymorphisms with $\mathrm{CP}$.

The targeted genes whose variants were associated with $\mathrm{CP}$ in this study - endothelial NO synthase, factor 7, plasminogen activator inhibitor-1, and lymphotoxin - are related both to inflammation and coagulation and are active at the surface of vascular endothelium $(13,14-16)$. The interaction of inflammation and coagulation is apparently important in the genesis of $\mathrm{CP}$ in very preterm, and perhaps also in more mature, infants (8). Some of these genes are also involved in anti-oxidant and anti-excitotoxic defense. eNOS and ADRB-2 influence regulation of vascular tone and can alter blood flow to and within the brain and placenta and alter responsiveness of the vasculature to infection, pro-coagulant state, hypoxia, or hyperoxia. Some of the targeted genes have actions that could influence the development or function of the placenta or nervous system by additional and less explored mechanisms, as for example the involvement of these molecules in memory consolidation and in synaptic plasticity, potentially affecting motor and cognitive function.

Our observations are in relatively small numbers and obviously require replication. It may be genes or sequence variants in linkage disequilibrium with those we have identified, rather than the targeted genes or SNPs that are related to CP. Only further study will clarify this. Furthermore, while the associations we and others report relating genetic variants to a variety of neonatal illnesses or later outcomes are attractive because they suggest underlying pathobiologic processes, it must be acknowledged that genotype-disease associations are often difficult to replicate $(17,18)$. "Journals are littered with studies reporting an association between genetic variation and diseaserelated outcomes... [but]...few published reports of significant associations can be replicated unequivocally." (18)

We reach the tentative conclusion, subject to efforts to replicate these findings in a large and relatively homogeneous population that there may be a genetic component in vulnerability to $\mathrm{CP}$ in premature infants, and that inflammation, coagulation, and disordered vascular responsiveness contribute to this disorder.

Acknowledgments. The authors thank Michael Grow, Carita Elfstrom, Calvin Mano and Arkadiy Silbergleit for their efforts and expertise in developing the genotyping reagents used for this work, Poulina Uddin for her assistance with genotyping experiments, and Meredith Anderson for her invaluable contributions to the analysis.

\section{REFERENCES}

1. Hoppe C, Klitz W, Cheng S, Apple R, Steiner L, Robles L, Girard T, Vichinsky E, Styles L CSSCD Investigators 2004 Gene interactions and stroke risk in children with sickle cell anemia. Blood 103:2391-2396

2. Grether JK, Nelson KB, Walsh E, Willoughby RE, Redline RW 2003 Intrauterine exposure to infection and risk of cerebral palsy in very preterm infants. Arch Pediatr Adolesc Med 157:26-32

3. Cheng S, Grow MA, Pallaud C, Klitz W, Erlich HA, Visvikis S, Chen JJ, Pullinger CR, Malloy MJ, Siest G, Kane JP 1999 A multilocus genotyping assay for candidate markers of cardiovascular disease risk. Genome Res 9:936-949

4. Freeman GH, Halton JH 1951 Note on an exact treatment of contingency, goodness of fit and other problems of significance. Biometrika 38:141-149

5. Breiman L, Friedman J, Olshen R, Stone C 1984 Classification and Regression Trees. Wadsworth, Pacific Grove

6. Lane DA, Grant PJ 2000 Role of hemostatic gene polymorphisms in venous and arterial thrombotic disease. Blood 1517-1532

7. Landau R, Xie HG, Dishy V, Stein CM, Wood AJ, Emala CW, Smiley RM 2002 Beta2-adrenergic receptor genotype and preterm delivery. Am J Obstet Gynecol 187:1294-1298

8. Leviton A, Dammann O 2004 Coagulation, inflammation, and the risk of neonatal white matter damage. Pediatr Res 55:541-545

9. Chorioamnionitis and cerebral palsy in term and near-term infants. JAMA 290:26772684

10. Redline RW, Wilson-Costello D, Hack M 2002 Placental and other perinatal risk factors for chronic lung disease in very low birth weight infants. Pediatr Res 52:713-719

11. Hamvas A 2000 Disparate outcomes for very low birth weight infants: genetics, environment, or both? J Pediatr 136:427-428

12. Grether JK, Hoogstrate J, Walsh-Greene E, Nelson KB 2000 Magnesium sulfate for tocolysis and risk of spastic cerebral palsy in premature children born to women without preeclampsia. Am J Obstet Gynecol 183:717-715

13. Hooper WC 2004 The relationship between inflammation and the anticoagulant pathway: the emerging role of endothelial nitric oxide synthase (eNOS). Curr Pharm Des 10:923-927

14. Bhagat K, Vallance P 1999 Effects of cytokines on nitric oxide pathways in human vasculature. Curr Opin Nephrol Hypertens 8:89-96

15. Voetsch B, Loscalzo J 2004 Genetic determinants of arterial thrombosis. Arterioscler Thromb Vasc Biol 24:216-229

16. Levi M, Keller TT, van Gorp E, ten Cate H 2003 Infection and inflammation and the coagulation system. Cardiovasc Res 60:26-39

17. Cardon LR, Bell JI 2001 Association study designs for complex diseases. Nature Rey Genet 2:91-99

18. Colhoun HM, McKeigue PM, Davey Smith G 2003 Problems of reporting genetic associations with complex outcomes. Lancet 361:865-872 